\title{
Accreditation Comes to Public Administration
}

\section{- An Editorial -}

\author{
DAVID R. MORGAN \\ University of Oklahoma \\ President, Midwest Review of Public Administration
}

It is not being called accreditation, but the creation of a list of "approved" master's programs in public administration looks suspiciously like just that. Sometime in 1980 the National Association of Schools of Public Affairs and Administration (NASPAA) will establish a list of those master's programs that are considered as meeting certain standards and thus merit the label "approved." Perhaps public service education has reached the point where this step was inevitable if not essential. But what does this process mean to the future of public service education? Are there potential problems associated with this effort? What institutions appear most likely to benefit from such a process?

These questions cannot be dealt with in any depth here. But it does seem appropriate to address several broad issues associated with the process of creating and implementing standards in public service education (officially NASPAA cannot accredit anyone at this time, since it must first be accredited by the Council on Post Secondary Education). In particular we might ask: (1) what accreditation means in light of the nebulous professional nature of public administration; (2) whether standards as currently promulgated grant equal treatment to p.a. programs operated within political science departments; (3) what effect accreditation may have on efforts to create innovative and flexible master's programs.

Should we have accreditation, whether called that or not, in a field of study that has yet to establish an unequivocal claim to professionalism? In a recent Public Administration Review article, Richard Schott reflects a not uncommon view that public administration may be an "occupation, an activity, an applied art - but it is certainly not a true profession." The foct is, considerable legitimate disagreement continues as to just what it is a p.a. program is designed to produce. How do we educate administrative generalists or policy leaders, for that matter? Do we really know enough at this point to create for such people a "professional" post-bachelor's degree program that must follow fairly explicit guidelines? If p.a. is more a craft than a profession, is it appropriate, for example, to insist that at least 75 per cent of the graduate program's full-time faculty must hold an earned doctorate or equivalent (as NASPAA requires)?

NASPAA guidelines mandate that the master's program have an 139 
identifiable budget, and the director (and/or program faculty) must have jurisdiction over appointment and promotion of program faculty. How will this work in programs contained within political science departments? Most public service educational activities in this country are still conducted within political science departments. Many of the larger and more prestigious programs, of course, have a separate existence. Are NASPAA standards designed to give an equal chance for approval to political science based programs or might there be a bias toward those separately established? (All members of NASPAA's Executive Council are connected with non-political science programs).

Finally, will standards permit the essential flexibility and innovativeness necessary to meet the educational needs especially of practicing administrators? Various surveys conclusively show that a majority of MPA students are significantly older than most graduate students and are likely to be employed full or part time. Surely special innovative efforts are required to serve such a group. The NASPAA standards explicitly proclaim the need for creative educational arrangements. But the requirements imposed on off-campus programs make one wonder. For example, they insist that full-time parent-program faculty must be continuously involved in the off-campus program. Moreover, "curriculum requirements, admission practices, student counselling and qualifications of faculty must be equivalent to the parent program." Just how much innovativeness can exist under such structures? Granted, off-campus programs require careful scrutiny. But what about intensive, short duration seminars as a scheduling alternative? Will these meet the standards?

At the moment, of the 160 or so master's progroms in existence about 60 have gone through the first step of the review process (a comprehensive self-study). How many will eventually survive remains to be seen. Here we might compare p.a. graduate programs with their MBA counterparts. Accreditation has been a fact of life for years in business education, of course. What has been the result? MBA programs are loaded with prerequisites (often including calculus and matrix algebra), a host of mandatory courses, and a total number of hours that cannot be completed ordinarily in less than two years. Is this the model we want to pursue in public administration, or do we need greater flexibility to serve our more diverse clientele?

All this is not to suggest that standards are unnecessary or that some form of accreditation may not eventually be useful in the field of public service education. But such an effort will have to be undertaken with great care and considerable caution. Otherwise only the largest, elite schools may be able to qualify. Surely small programs and innovative formats should not automatically lose out. 